Servizio di Genetica

Medica, Ospedale

Bambino Gesu',

Piazza S Onofrio 4,

00165, Rome, Italy.

A Giannotti

M C Digilio

M G Obregon

Neonatal Unit,

Bambino Gesu'

Hospital, Rome, Italy.

$Q$ Virgili

A.M Guadagni

Department of

Pathology, S

Salvatore Hospital,

L'Aquila, Italy.

$\mathrm{T}$ Ventura

Department of

Human Genetics,

Department of Public

Health and Cell

Biology, IInd

University, Via

Carnevale, Rome

Italy.

B Dallapiccola

Correspondence to

Dr Giannotti.

Received 15 January 1992.
Revised version accepted

26 March 1992.

\title{
Familial postaxial acrofacial dysostosis syndrome
}

\author{
A Giannotti, M C Digilio, Q Virgili, M G Obregon, A M Guadagni, T Ventura, \\ B Dallapiccola
}

Most known cases of postaxial acrofacial dysostosis syndrome (POADS) are sporadic. The familial case of Robin sequence and oligodactyly occurring in a mother and her two sons, reported by Robinow and $\mathrm{Chen}^{1}$ as a previously unrecognised malformation syndrome, was later regarded as an example of POADS $^{2}$ and autosomal dominant inheritance of this condition was suggested. However, other familial cases have been reported in three pairs of sibs born to healthy, unrelated parents. ${ }^{3-5}$ In addition, one patient was born to consanguineous parents. ${ }^{6}$ These observations argue for autosomal recessive inheritance of this syndrome (MIM 263750). We report here a family with two affected sibs which support this.

Case 1 (figure A,B) is a male infant, the last child of a sibship of four. The parents were non-consanguineous and clinically normal.
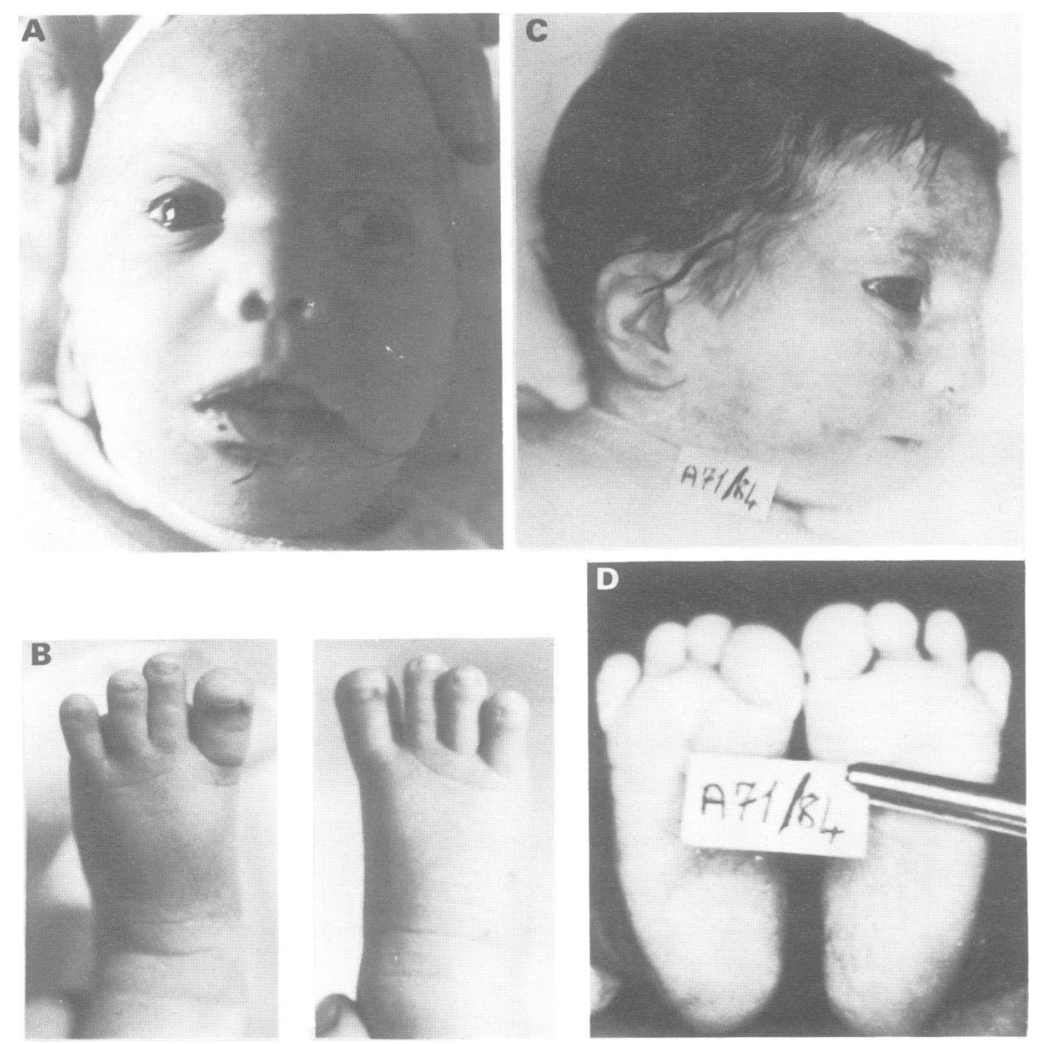

Facial appearance and feet of case $1(A, B)$ and case $2(C, D)$.
The baby was delivered by caesarean section at term after an uneventful pregnancy. Birth weight was $2700 \mathrm{~g}$, length $48 \mathrm{~cm}$, and head circumference $35 \mathrm{~cm}$. Clinical evaluation at 1 month showed downward slanting palpebral fissures, bilateral coloboma of the eyelids, cleft of the hard palate, glossoptosis, micrognathia, low set, dysmorphic ears, ulnar deviation of the hands at the wrist, and absence of the fifth fingers and toes. $X$ ray examination of the upper and lower limbs showed short forearms with bilateral radioulnar synostosis and absence of the fifth digital ray of the hands and feet. The karyotype was normal.

An older sister of the patient (case 2, figure C,D) died at 13 days of life. She had a constellation of anomalies similar to the ones detected in the patient, including cleft hard palate, micrognathia, low set and malformed ears, absence of the fifth digital rays of the upper and lower limbs, and bilateral ocular glaucoma. The neonatal period was complicated by recurrent cyanosis and apnoea which required continuous medical care. Photographic evaluation of this patient suggested a diagnosis of POADS.

These two sibs, together with four previously documented familial cases of POADS, strongly support autosomal recessive inheritance of this condition. Thus, a one in four recurrence risk should be given to the patient's parents. At present, the existence of genetic heterogeneity in POADS, in our opinion, is supported only by the familial observation of Robinow and Chen. ${ }^{1}$ However, critical reevaluation of that syndrome does not obviously suggest that it should be lumped with POADS.

1 Robinow $M$, Chen $H$. Genée-Wiedemann syndrome in a family. Am f Med Genet 1990;37:293.

2 Meinecke P, Wiedemann HR. Robin sequence and oligodactyly in mother and son - probably a further example of the postaxial acrofacial dysostosis syndrome. Am $\mathcal{F}$ Med Genet postaxial acrofacial

3 Fineman RM. Recurrence of postaxial acrofacial dysostosis syndrome in a sibship: implications for genetic counseling. f Pediatr 1981;98:87-8.

4 Opitz JM, Stickler GB. The Genée-Wiedemann syndrome, an acrofacial dysostosis. Further observation. $A m \mathcal{F}$ Med Genet 1987;27:971-5.

5 Ogilvy-Stuart AL, Parsons AC. Miller syndrome (postaxial acrofacial dysostosis): further evidence for autosomal recessive inheritance and expansion of the phenotype. $\mathcal{F} \mathrm{Med}$ Genet 1991;28:695-700.

6 Smith DW, Pashayan H, Wildervanck LS. Case report 28. Synd Indent 1975;3:7-13. 